\title{
Physics for the Modern Warrior: Bringing Innovation to Physics Instruction at the United States Military Academy
}

\author{
Michael P. Shannon, Lance K. Calvert \\ Department of Physics, United States Military Academy, West Point, NY
}

\begin{abstract}
$\underline{\text { Abstract }}$
The mission of the United States Military Academy is to educate, train, and inspire the Corps of Cadets so that each graduate is a commissioned leader of character. Every cadet who graduates from West Point receives a commission in the United States Army and subsequently serves as an Army officer in a myriad of capacities. This charge has taken on a much greater significance in light of the events of September 11, 2001. The world has changed greatly, therefore the Army must respond by developing leaders who understand the complicated technological issues of today.
\end{abstract}

The challenges for today's Army officers are much different than those of the Cold War era. Army leaders must understand complex devices like dirty bombs, computer-based technology, and countless types of high-tech gadgets that shower today's battlefield. The challenge is to ensure that future leaders are able to understand how these devices work and the methods needed to prevent an enemy from using them against our forces. At the United States Military Academy, all third class cadets (sophomores), regardless of academic major, complete two semesters of calculus-based physics. The USMA Department of Physics has worked diligently to develop courses that are relevant, challenging, rigorous, and pedagogically sound.

This paper discusses the manner in which physics concepts are presented in the classroom. Specifically, how we motivate the cadets, by bringing the military relevance of physics into the classroom and the laboratory. We place a heavy emphasis on the focused presentation of theoretical concepts coupled with innovative and interactive demonstrations and exercises centered around actual military hardware. A selective curriculum of physics topics, tailored to meet our program goals of educating future officers, has been developed and implemented. This paper will highlight the techniques that provide a positive driving force to cadet learning and result in an Army officer with a solid understanding of the fundamental principles of physics on the modern battlefield.

$\underline{\text { Introduction }}$

On the banks of the Hudson River, approximately 50 miles northeast of New York City, sits the United States Military Academy. The oldest of the service academies, West Point was established by President Thomas Jefferson in 1802 to serve as an institution dedicated to the 
teaching of the art and sciences of warfare. For over 200 years, West Point has stood as a hallmark leadership and academic institution within the United States. The academy has long held the prestige of being one of the oldest and finest engineering schools in the country. Aware of our young nation's need for engineers, Colonel Sylvanus Thayer, (USMA Superintendent from 1817-1833) made civil engineering the foundation of the curriculum. For its first half century, USMA graduates were largely responsible for the construction of the nation's railway lines, bridges, harbors and roads. ${ }^{1}$

The focus of West Point is unchanged over the past 200 years; that of commissioning officers for America's Army. The mission of West Point, shown in Figure 1, exemplifies the ideals of the academy. The focus of the entire curriculum is on one essential purpose; to develop leaders of character for the United States Army. All other purposes are secondary. Through the years, the academic curriculum of West Point has changed to include many areas of study. Although the curriculum is now as diverse as many other U.S. colleges and universities, the requirement for each cadet to be well rounded in math and science stills exists.

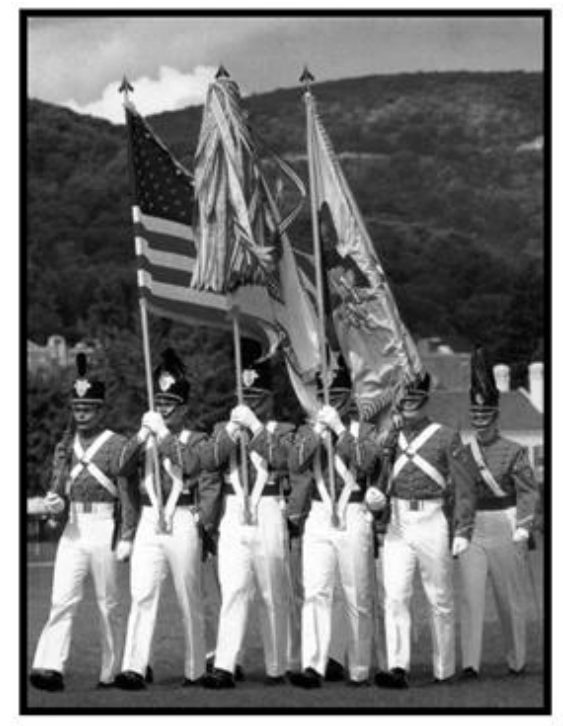

\author{
Mission of the United States Military Academy: \\ "To educate, train, and inspire the Corps of Cadets so \\ that each graduate is a commissioned leader of \\ character committed to the values of Duty, Honor, \\ Country; professional growth throughout a career as \\ an officer in the United States Army; and a lifetime of \\ selfless service to the nation."
}

\title{
DUTY - HONOR - COUNTRY
}

Figure 1. Mission of the United States Military Academy²

Over recent years, the academy's leadership has taken a hard look at the needs of the $21^{\text {st }}$ Century Army officer. This introspective look produced a document called "Educating Future Army Officers for a Changing World," "3 wich outlines the focus and vision for the West Point academic program. The thesis of this document is that a quantitative way in which to measure what every cadet can do upon graduation must exist. To ensure consistency among its graduates, every West Point cadet must complete the 27-course core curriculum which spans the minimum knowledge every graduate must possess and constitutes what is known as the professional major. ${ }^{4}$ Each cadet then goes on to complete a 3-course engineering sequence and their academic major.

Within the core curriculum resides the requirement for every cadet to complete two semesters of a calculus-based physics course. During the freshman or "plebe" year, every cadet 
completes two math courses in discrete dynamical systems and calculus in addition to two semesters of chemistry. These courses are followed by two courses in physics, PH 203 and PH 204, as well as two math courses in calculus and probability and statistics, an environmental studies course, and a computer programming course in the sophomore or "yearling" year.

\section{Challenges of Teaching Physics at West Point}

Teaching PH 203 and PH 204 is a daunting challenge. Most college students who embark upon a calculus-based "college physics experience" are math, science or engineering majors who have both the desire and motivation to learn concepts such as Newton's Laws and Huygen's principle. Further, most traditional university physics courses have 7 plus contact hours per week whereas West Point physics courses have only 3.5 contact hours per week. Figure 2 captures some of these challenges and our current success rate.

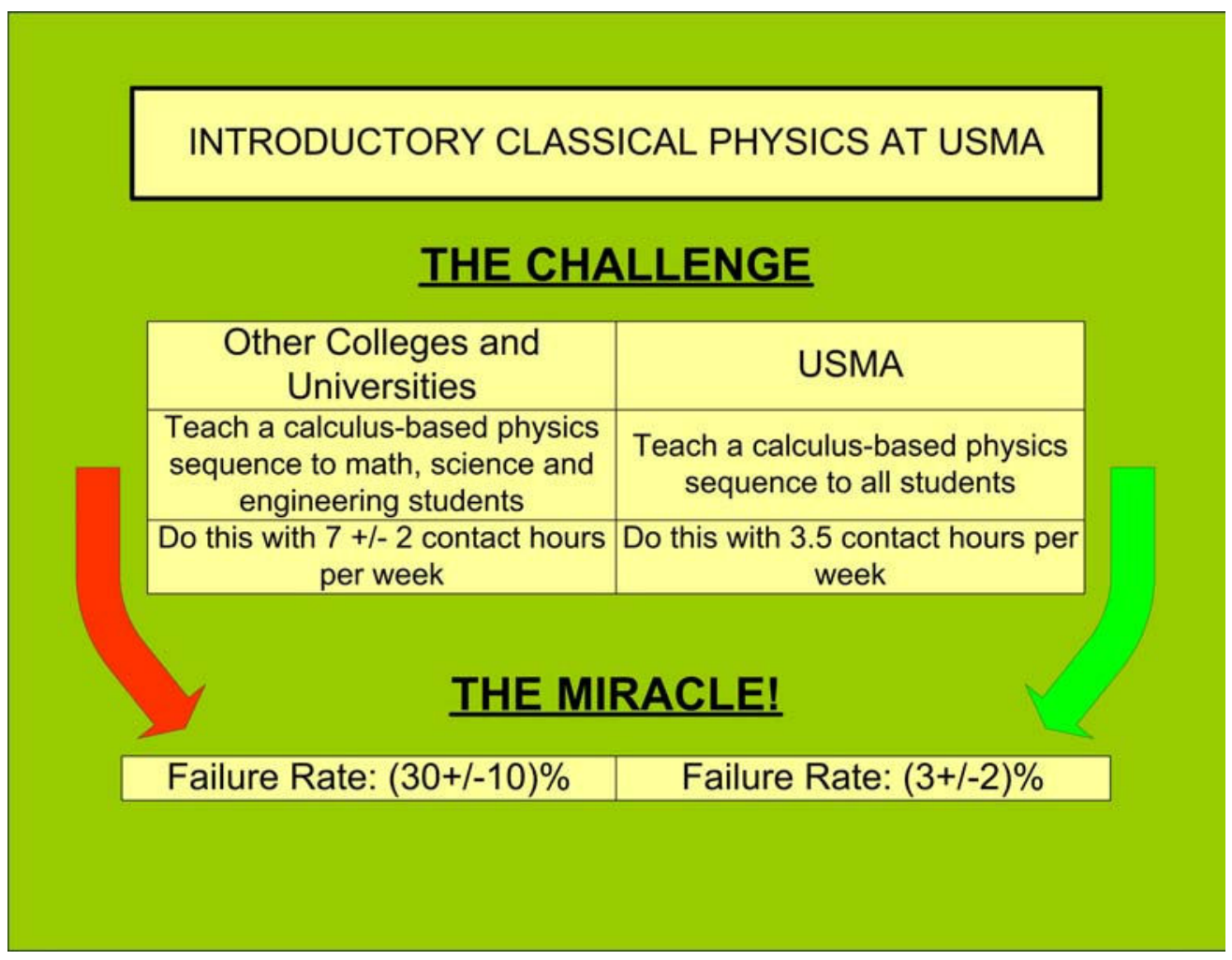

Figure 2. Challenges and Success Rate of Classical Physics

The overwhelming reason for this success rate is the quality of student that enters West Point. The average West Point cadet entering the class of 2007 scored 1280 on the SAT, was in the top $10 \%$ of his or her high school graduating class and was a leader both in extra-curricular and community activities. For these reasons, the Princeton Review rated West Point as the Toughest College to Get Into for 2004..$^{5}$ Some of the other reasons for the tremendous success rate in the core physics courses are listed below:

- USMA student support mechanisms

- Small section size which leads to more individual attention 
- Well-prepared instructors who motivate cadet learning

- Instructors who are readily available for additional instruction (office hours)

- USMA instructor support mechanisms. ${ }^{6}$

Mathematical preparation is always a concern for college-level physics courses. This concern is also a reality here at West Point. The success of cadets in the core physics program seems to suggest that the cadets are as adequately prepared in mathematics as those entering other universities. This conclusion is confirmed in the comments of Professor Joseph Pizzo, Professor of Physics at Lamar University who twice served as a visiting professor in the USMA Department of Physics, "I found the cadets to be well prepared to take PH201 and PH202. I noticed some concern on the part of the physics department about the mathematics background of the cadets, but this concern is common at all universities. The cadets at West Point are just as well prepared mathematically as at any other university. ${ }^{7}$

\section{Overview of PH203 and PH204}

The physics program at the USMA is a two-semester, calculus-based program. The sequence consists of PH203 and PH204 for the first and second semesters respectively with the former a prerequisite for the second. Both courses are required for all graduating cadets regardless of academic major. This requirement results in several issues in the classroom that must be overcome including teaching to students that are motivated to learn physics as part of a base for their academic major, as well as those non-science and non-engineering majors that are required to take the class, but are less motivated to master the subject.

Another challenge within the core physics program is how to instruct the same course material to $850+$ students that are split into 64 sections taught by 16 different instructors. Cadet class standing is an immensely important aspect of the cadet experience at West Point. It impacts the cadet's choice of military specialty and first duty assignment upon graduation, and will continue to follow the cadet throughout their military career. Therefore, consistent grading across the board is imperative. To overcome this challenge, the Department of Physics has developed and implemented a pedagogy that is adhered to by all faculty and a well-defined grading rubric in which standards for performance are clearly defined and understood by the graders. Our focus in this paper is on the method of instruction, and how it provides a sound, active learning environment, and provides motivation for cadet learning.

The program is taught in a model-coach-fade method. ${ }^{8}$ All instructors spend a lesson or two modeling the physics concepts and a problem through interactive demonstrations that involve military applications. Then a lesson is spent coaching the cadets through some exercises and problems applying the concepts from the current block of instruction. This is often accomplished through blackboard work in teams or individuals. Other techniques in this phase include the use of peer instruction techniques and experimental design problems based on the posing of military context questions. ${ }^{9}$ Finally, the instructors fade from the picture, let the cadets take charge of the learning through student chosen exercises, and assess the student learning through in class instructor and course wide exams. Examples of how the department incorporates military relevance into this instruction method and the program as a whole will be explained in the remainder of this paper. 
It is well known that in order to improve the motivation of the students in a classroom, the teacher must find ways to make the material seem pertinent to the student's future. ${ }^{10}$ At West Point, this task has been accomplished by structuring our two semester core physics program within the framework of a single military operation that not only gives structure to the course, but also provides a means for the department to connect the many physics topics to the military applications that these young men and women will be exposed to in their Army career.

The military operation that encompasses the two semester program begins with the "Call to War." This event, the detonation of a nuclear device in a territory considered to be an ally of the United States, triggers a build up of forces and the initiation of the operation that will carry us through the next 80 lessons of the two semester program. As depicted in Figure 3, the operation continues with a Reconnaissance of the Battlefield, Preparation of the Battlefield, Attack, and culminates in a Defense phase. Within each phase, the physics principles are presented and discussed. Throughout the process we maintain a focus on the military application(s) to which these principles are relevant.

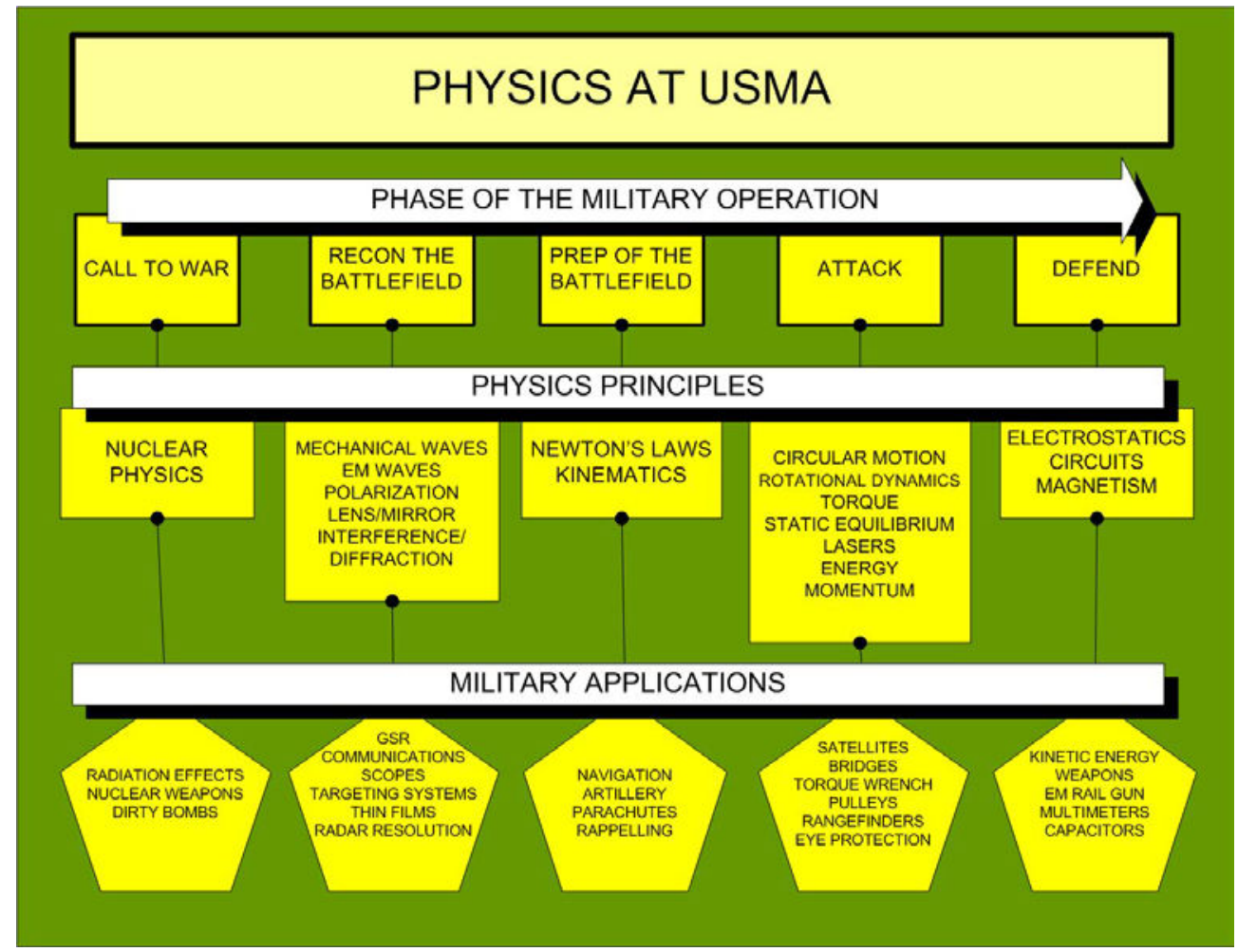

Figure 3. Concept of the Operation for PH203/PH204

The order in which we fight the military operation also dictates, to some degree, the order in which we present the physics principles. In most colleges and universities, the physics courses begin with the introduction of vector quantities, one- and two-dimensional motion, and build up through Newton's Laws. Very rarely will a first semester physics student encounter nuclear physics or electromagnetic waves. Not so in our program. In the opening phase of the operation, "Call to War," the students are presented with nuclear physics and its military application to radiation effects and nuclear weapons. The second phase, "Reconnaissance of the 
Battlefield," requires the military use of detection equipment to include binoculars, weapon sighting systems, and radars. Therefore, this phase focuses on the physics behind these systems to include mechanical and electromagnetic waves, lenses and mirrors, and interference and diffraction. It is not until the "Preparation of the Battlefield" phase that the course presents oneand two-dimensional motion, kinematics, Newton's Laws, and how they apply to navigation, military artillery and bomb missions, or Airborne parachute operations. The remainder of the operation and the topics and applications covered are shown in Figure 3.

\section{Military Relevance Brought to Life in the Classroom}

Classroom instruction provides a superb opportunity to bring to the life the military applications of many physics principles. In addition to using standard classical physics demonstrations, i.e. a cart on a ramp or the laser and a diffraction grating, numerous pieces of actual military hardware are brought into the classroom to stimulate discussion about the physics concepts associated with the equipment. For example, during the Reconnaissance of the Battlefield Phase, optics concepts are the main focus. Army equipment such as military binoculars and laser aiming sights are used to demonstrate the principles of magnification, photon energy, diffraction, etc. From this discussion emerges a chalkboard example problem in which the cadets actually calculate these quantities. In almost every lesson, cadets are exposed to an actual piece of military hardware and the physics used to make it work. Figure 4 shows some of the Army hardware demonstrated in the classroom and the associated physics concepts.

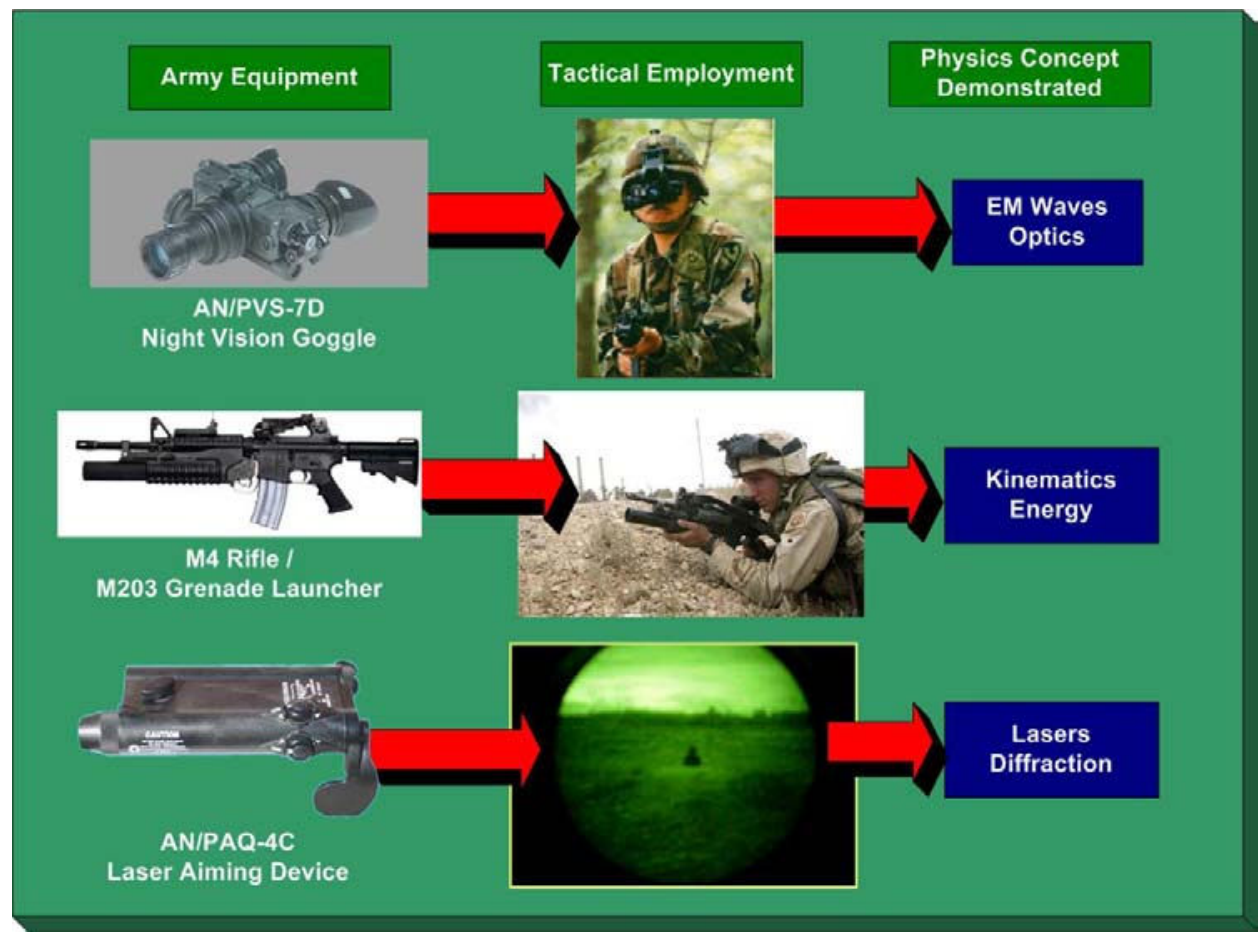

Figure 4. Examples of Army Equipment Used in Classroom Demonstrations

The military relevance thread does not stop with the classroom instruction. It is continually stressed through demonstrations and laboratory experiments that include the use of 
military equipment such as radiation detectors, night vision devices, projectile weapons systems, parachutes, laser rangefinders, etc. There is also a requirement for the students, working as a team, to present military application briefings of 7-10 minutes at various points throughout the program that highlight military hardware with a focus on how the systems are employed and how the physics they have just studied is applied. Furthermore, in our method of instruction, the exercises and problems worked in the classroom as well as on exams are rich with military content. The following discussion will outline how two key classical physics topics are presented in a militarily relevant context.

\section{Presentation of Thin Film Interference}

In the first semester of the program the theory of waves, both mechanical and electromagnetic, is introduced as part of the reconnaissance of the battlefield. Here we want the cadets to understand how these waves and the various regions of the electromagnetic spectrum are used in the military. Several of these applications are shown in Figure 5. The message is that by understanding both the friendly and enemy capabilities in these areas, we can take advantage of physics and technology to defeat our foes. This instruction includes theory and applications for the traveling and standing properties of both types of waves, diffraction, resolution, and interference. Specifically, the theory of interference is applied to electromagnetic waves in a thin-film interference application. While most texts cover and present results for a thin film of soap or other media in air, our course requires the student to analyze and understand the geometry of the problem and apply the appropriate thin film physics based on this geometry. We also look at several applications of thin films in a military context and have the cadets solve problems in this manner.

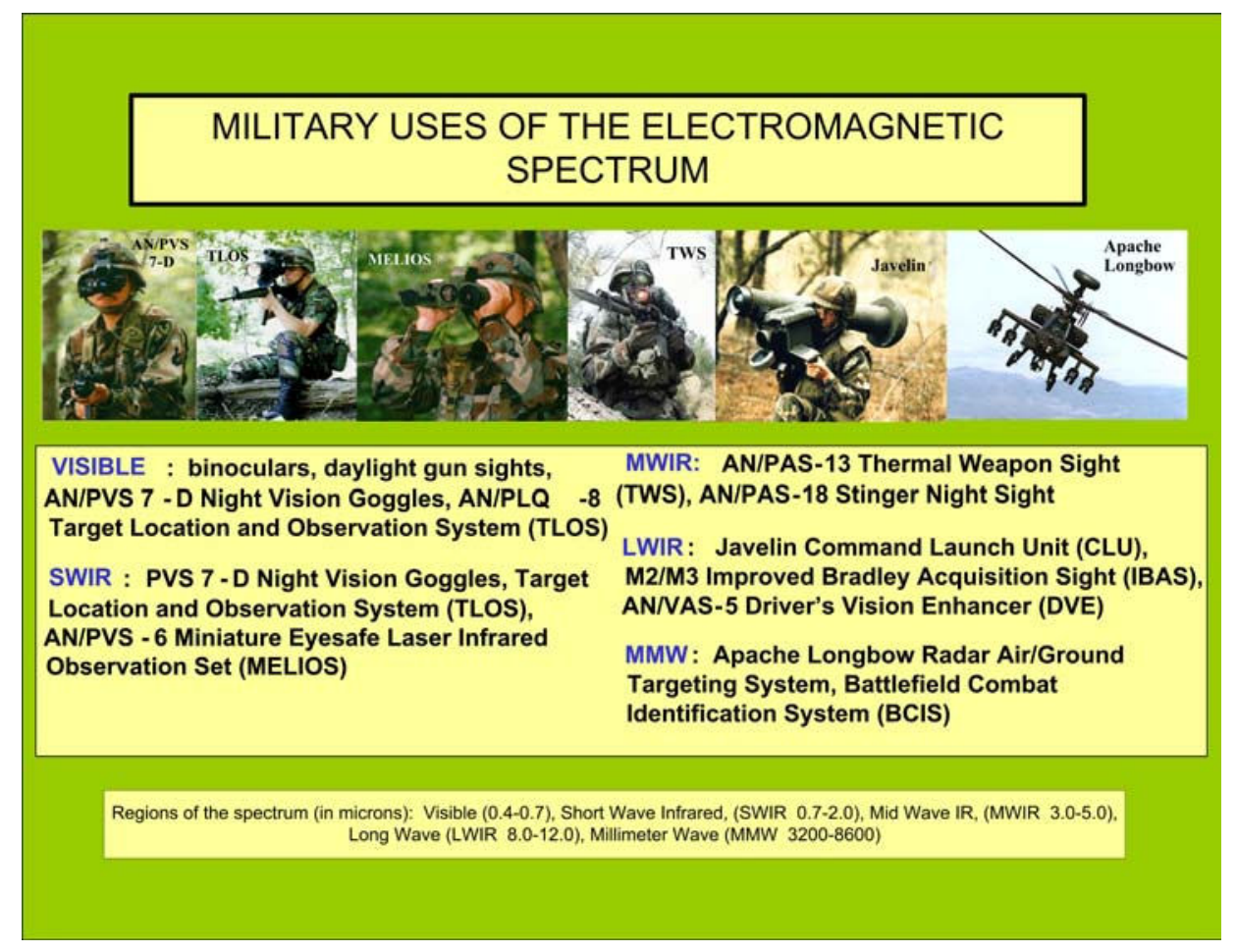

Figure 5. Military Applications of the Electromagnetic Spectrum 
At the point in the semester when we study thin film interference, the cadets have already studied waves, both mechanical and electromagnetic, to include propagation properties, reflections at hard or soft boundaries, and interference between two coherent waves. They have also been introduced to the optics of polarization, reflection and refraction, and understand the concept of index of refraction. Finally, in the lessons directly preceding the thin film classes, the cadets study interference between waves due to a path length difference in a Young's double-slit experiment, as well as a path length difference induced by media of different indices of refraction. With the information they already know about waves and interference, it is not a major leap to apply this physics, coupled with a discussion of phase change on reflection for an electromagnetic wave, to a thin film interference problem. In fact, most cadets find this transition relatively easy. At this point we introduce the various military applications and the different geometries which require analysis and deeper understanding of the physics.

Some examples of the military applications of thin films include: anti-reflection coatings to defeat detection systems, laser eye protection, and night vision devices. These systems can provide the basis for a multitude of context rich questions for classroom discussion or exams. Some examples of these problems used during the Fall 2003 semester follow.

Example 1: Military binoculars have thin film coatings on the objective lenses to reduce reflection. The index of refraction of the film is less than that of the glass, which is 1.45 . Given that the minimum thickness of the coating to destructively interfere in reflection with yellow light $(\lambda=550 . \mathrm{nm})$ is $100 . \mathrm{nm}$, calculate the index of refraction of the film.

Example 2: It has recently been discovered that terrorists have acquired a laser weapon that emits a beam at a wavelength of $\lambda=896 \mathrm{~nm}$, and an intensity level high enough to cause eye damage. The military has developed a thin-film for application to the front surface of plastic aviation helmet visors that will cause this wavelength to destructively interfere in transmission (i.e., the laser does not penetrate the goggles due to the film). If the minimum film thickness required is $313 \mathrm{~nm}$, calculate the index of refraction of the thin film? Assume the index of refraction of the plastic is higher than that of the film.

\section{$\underline{\text { Presentation of Rotational Dynamics }}$}

As in a conventional classical physics course, Newtonian mechanics is covered in much detail. Following a rigorous study of Newton's Laws, rotational dynamics and torque are presented. These concepts are modeled in a traditional classroom format by studying the fundamentals such as angular velocity, angular acceleration and moment of inertia. Once a full theoretical basis is established, several military applications are introduced. Helicopter are ubiquitous on the modern battlefield, therefore several helicopter examples are used. Additionally, the pulley can be of great importance in tactical/combat situations. With each of these applications, cadets have the opportunity to solve several Army-relevant problems. Some examples of these problems used during the Fall 2003 semester follow.

Example 1: You receive a mission in your company Command Post to launch a UH-60 Blackhawk helicopter with a quick reaction force to an area $5 \mathrm{~km}$ to the north of your assembly area. Your unit always has a helicopter that has completed preflight inspections and all 
performance tests on standby for such a mission. You and your co-pilot, CW3 Flysalot jump in and start the main engines to begin your mission. The main rotor system takes 15.6 seconds, under constant angular acceleration, to go from rest to full operating RPM of 258. This intrigues you, and upon completion of your flight you analyze the rotational physics of the start sequence. First, you obtain the following Main Rotor data from the UH-60L Operator's Manual ${ }^{10}$ :

$\begin{array}{ll}\text { Mass of one rotor blade (m): } & 138 \mathrm{~kg} \\ \text { Length of one rotor blade (L): } & 7.68 \mathrm{~m} \\ \text { Chord of one rotor blade (W): } & 0.481 \mathrm{~m} \\ \text { Area of rotor disk: } & 210.15 \mathrm{~m}^{2} \\ \text { Operating RPM: } & 258 \mathrm{rpm}\end{array}$

With this data, complete the following tasks:

a.) Calculate the angular speed of the main rotor system at operational RPM; b.) calculate the constant angular acceleration of the main rotor system during the start sequence; c.) calculate the angular displacement that the main rotor system rotates through during the start sequence; d.) calculate the linear (tangential) speed of the rotor tip at operational RPM; e.) given that the blades rotate about the mast with an offset of $0.500 \mathrm{~m}$ from the root of the blade to the center of rotation, calculate the rotational inertia of the main rotor system (four blades); f.) given the main rotor blade is attached to the mast by a coupling at its root, calculate the force on the coupling due to the rotor blade at operational RPM; g.) Assume that the engines apply a force tangent to the circular main rotor gearing at a distance of $0.442 \mathrm{~m}$ from the mast of the rotor system. Calculate the magnitude of the force. Neglect the inertia and friction inherent in the gearing and mast. The main rotor system rotates $\mathrm{CCW}$ when viewed from above; h.) we know from Newton's third law that the gearing will also exert an equal and opposite force onto the helicopter which will result in a rotation of the helicopter about the mast if its rotation were not prevented by the tail rotor assembly. If the tail rotor is $22.6 \mathrm{~m}$ behind the mast of the helicopter, calculate the required force (magnitude and direction) that is required to prevent this rotation; and i.) if the tail rotor rotates at $17600 \mathrm{rpm}$, and has a radius of $1.25 \mathrm{~m}$, calculate the tip speed of the tail rotor.

Example 2: During routine tactical operations, one of your vehicles falls into a large ditch and must be hauled out in order to continue operations. You instruct one of your soldiers to run a cable from your vehicle to the entrapped vehicle over a rock formation in order to prevent the cable from being buried in the ground (you will ignore the friction which exists between the rock and the cable). The winch on your HMMWV (Highly Mobile, Multi-Purpose Wheeled Vehicle) consists of a motor and a drum around which the cable wraps. The motor applies 250 $\mathrm{N}$ m of torque to the $20 \mathrm{~cm}$ diameter winch drum. The moment of inertia of the drum is $0.542 \mathrm{~kg}$ $\mathrm{m} .^{2}$ If the entrapped vehicle weighs $5200 \mathrm{~N}$, calculate the magnitude of its acceleration.

Both of these examples cover the entire spectrum of the physics associated with rotational dynamics in an extremely militarily relevant context. Once the cadets get over what they perceive as an "impossible" problem and draw a free-body diagram, they find that methodically solving the problem step-by-step produces a valid solution. Both of these problems proved very successful in conveying the necessary physics concepts to the cadets. In addition to in-class teaching examples, similar but shorter problems were used for examinations. 


\section{Conclusion}

The intent of this paper was to discuss the challenges associated with teaching classical physics at the United States Military Academy, along with various techniques used. We have demonstrated how the course and physics principles are developed with a focus on military operations and the applications that the cadets will see upon graduation. The result is a course that does not follow the traditional pedagogy for classical physics instruction, nor does it contain demonstrations that you would find in a sample classroom across the country. The classroom will have, however, multi-concept, military relevant problems and exercises, as well as hands on demonstrations with the various military hardware currently in service in the multiple war-zones throughout the world. The desired result is a highly interactive classroom and active learning environment that will bridge the gap between what a cadet is learning now and what the cadet needs to know as a future Army leader. A testament to how our program is influencing the young officers of today and tomorrow is an e-mail recently received from a USMA graduate (currently deployed with the $3^{\text {rd }}$ Infantry Division in Iraq) to the author requesting a copy of some of the course materials to be used in operations in his current theater of operation. ${ }^{12}$

The views expressed herein are those of the authors and do not purport to reflect the position of the United States Military Academy, the Department of the Army, or the Department of Defense

\section{Bibliography}

1. West Point Bicentennial: A Pictorial History of the First 200 Years of USMA. "USMA Home Page." United States Military Academy, West Point [web page online], accessed 22 December 2003; available from http://www.usma.edu/bicentennial/history/Preface.asp.

2. Cadet Leader Development System (CLDS). USMA Circular 1-101, USMA Office of the Superintendent, West Point, NY, June 2002.

3. Educating Future Army Officers for a Changing World: Operational Concept for the Academic Program of the United States Military Academy. USMA Office of the Dean, West Point, NY, 2002.

4. United States Military Academy Academic Program (Redbook)(AY 2003-2004). USMA Office of the Dean, West Point, NY, June 2003.

5. Best 351 Colleges: The Smart Students Guide to Colleges, 2004 Edition. Princeton, New Jersey: Princeton Review, August 2003.

6. Naessens, Edward Colonel. Department of Physics Teaching Philosophy. United States Military Academy Department of Physics, West Point, NY, July 2003.

7. Pizzo, Joseph. 1993 Visiting Professor's Report. United States Military Academy Department of Physics, West Point, NY, 1993.

8. Collins, A., Brown, J. S., \& Holum, A. (1991). Cognitive apprenticeship: Making thinking visible. American Educator, 6-46

9. Mazur, Eric, Peer Instruction: A User’s Manual, Prentice Hall, Inc., Upper Saddle, NJ, 1997. 
10. TM-1-1520-237-10, “Operator's Manual for Helicopter, Utility, UH-60A/L/EH-60A Blackhawk, Change 3”, Headquarters, Department of the Army, Washington D.C., 31 October 1996.

11. Gilliland, C. Herbert. "Just Give Me the Facts": Influences on Individual Choice of Learning Strategy at a Military Academy. Teaching and Learning in the Next Century, ed. Patricia Gandolfo, West Point, 1997.

12. Email correspondence (name withheld for operational purposes), USMA graduate, October 2003.

CPT MICHAEL SHANNON is an instructor in the Department of Physics at the United States Military Academy. CPT Shannon received an Army ROTC commission and a Bachelor of Science degree in Aerospace Engineering at Embry-Riddle Aeronautical University (ERAU) in Prescott, AZ. CPT Shannon holds a Master of Science degree in Aeronautics from ERAU as well as a Master of Science degree in Health Physics from Georgia Tech.

CPT LANCE CALVERT is an instructor in the Department of Physics at the United States Military Academy. CPT Calvert is a 1993 graduate of the United States Military Academy from which he received an Army commission as an Aviation Officer and a Bachelor of Science degree in Aerospace Engineering. CPT Calvert also holds a Master of Science degree in Optics from the Institute of Optics at the University of Rochester, New York. 